\title{
Le Thesaurus de I'Image Médicale de Strasbourg 026
}

Eur J Orthop Surg Traumatol (1998) 8: 182

A. Wackenheim $\dagger$

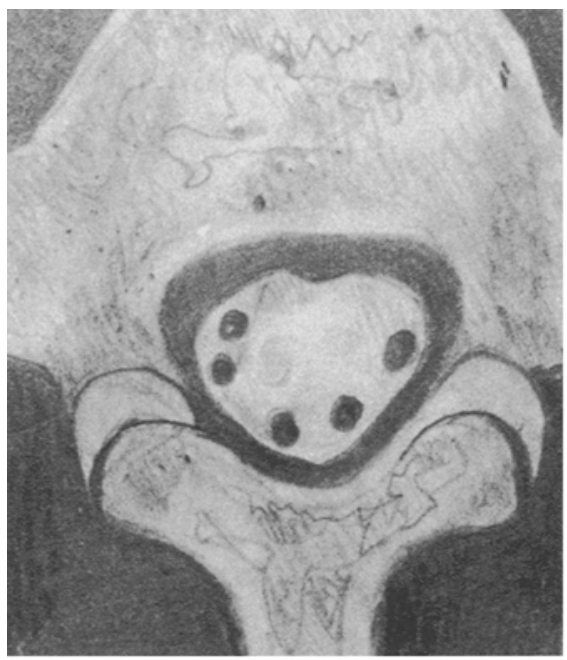

J66

Postsurgical calcified lumbar arachnoiditis (P) (CT)

Arachnoïde post-opératoire lombaire calcifiée (P) (TDM)

Lumbale verkalkte Arachnoiditis nach Chirurgie (P) (CT)

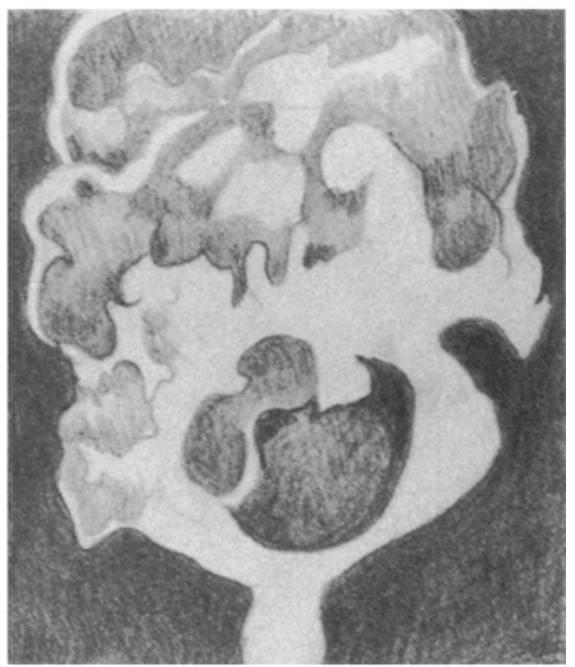

J108

Chordoma of the axis (S) (CT)

Chordome de l'axis (S) (TDM)

Chordom des Axis (S) (CT)

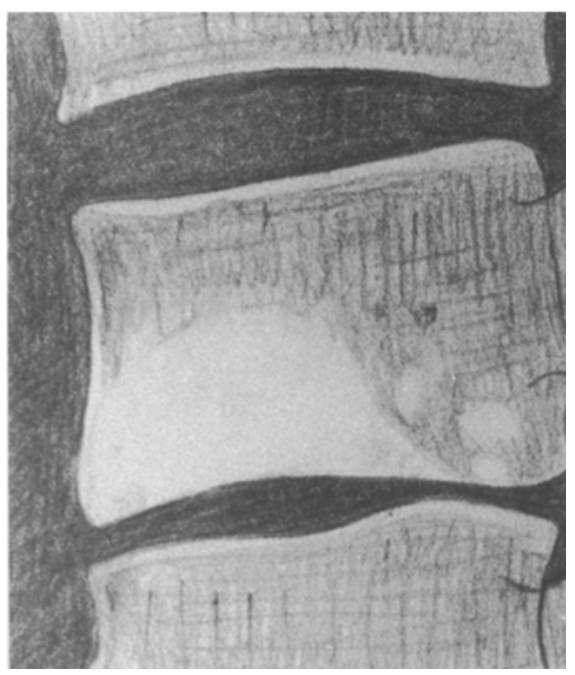

$J 101$

Vertebral arthrosis (osteochondrosis). Domelike osteosclerosis of the vertebral body (P) (RX)

Arthrose vertébrale. Ostéosclérose corporéale en dôme (P) (RX)

Spondylose. Domförmige Wirbelkörperosteosklerose (P) (Rö) 